\title{
KESTABILAN TRANSIENT PADA SISTEM KELISTRIKAN SULAWESI SELATAN
}

\author{
Andi Abdul Halik ${ }^{1}$ dan Adriani ${ }^{2}$ \\ Jurusan Teknik Elektro, Universitas Muhammadiyah Makassar, \\ Jl. Sultan Alaudin No. 259, Makassar, 90221, Indonesia \\ e-mail: halik@unismuh.ac.id,adrianiteknik@unismuh.ac.id
}

\begin{abstract}
Abstrak - Dalam penelitian ini kita mengamati sistem dalam kondisi transien dan membuat perkiraan batas kestabilan. Hal ini diperlukan untuk mendesain sistem sedemikian hingga mampu menahan gangguan besar. Studi ini dilakukan dengan menggunakan simulasi gangguan hubung singkat 3 phasa pada saluran transmisi bus Tello $150 \mathrm{kV}$. Studi ini menghasilkan perkiraan batas kestabilan berupa waktu pemutusan gangguan dalam saluran yang nilainya didapat dari batas waktu kehilangan sinkronisasi (loss of synchronism). Batas waktu tersebut menjadi acuan dalam setting peralatan proteksi di saluran transmisi untuk menghindari dampak negatif yang lebih besar akibat adanya gangguan. Simulasi dilakukan dengan menggunakan software Matlab, hasil simulasi memperihatkan bahwa lama gangguan dan letak gangguan hubung singkat 3 phasa, mempengaruhi kestabilan transien. Pada simulasi menunjukkan waktu pemutusan kritis tercepat diperoleh di saluran Tello Tello Lama sebesar 0.125 detik.
\end{abstract}

Kata kunci：Kestabilan Transien, Hubung Singkat, Waktu Pemutusan Kritis

\begin{abstract}
In this study, we observe the system in transient model and estimated stability limit. This is needed to design the system in such way so the system is able to withstand large disturbances. This study is done by using 3 phase short circuit simulation in the $150 \mathrm{kV}$ transmission line Tello bus. From this study, we obtained estimated stability limit in the form of disruption time which values are obtain from loss of synchronism time limit. This time limit become reference in protection equipment setting in the transmission line to avoid bigger negative impact caused by the disturbance. The simulation using Matlab software. The results shown that the time and position of 3 phase disturbance can affect the transient stability. The simulation results shown that the faster critical clearing time is obtained in Tello - Tello Lama Line for 0.125 second
\end{abstract}

Keywords : Transient Stability; Short Circuit; Critical Clearing Time

\section{PENDAHULUAN}

Salah satu faktor yang mempengaruhi kesejahteraan masyarakat adalah pertumbuhan kebutuhan listrik yang terus meningkat tiap tahunnya. Terkait hal tersebut, diperlukan suatu sistem kelistrikan yang memadai baik dari segi teknis maupun ekonomis.

Sistem tenaga listrik yang baik adalah sistem tenaga yang dapat diandalkan dan dapat melayani beban secara kontinu. Dalam pengoperasian sistem tenaga listrik pada setiap saat akan selalu terjadi perubahan kapasitas dalam sistem. Akibat perubahan tersebut mengharuskan setiap pembangkit untuk menyesuaikan daya keluarannya mengikuti perubahan beban pada sistem. Jika hal ini tidak dilakukan maka akan menyebabkan keseimbangan daya dalam sistem terganggu dan efesiensi pengoperasian sistem akan menurun.

Perubahan keadaan kerja dari sistem yang besar dan tejadi seketika disebut gangguan, hal ini dapat terjadi antara lain akibat adanya hubung singkat pada sistem tenaga listrik, penambahan beban secara mendadak dalam jumlah yang besar, pemutusan beban atau unit pembangkit dan lain-lain.

Untuk memberikan penyaluran tenaga listrik yang stabil, suatu sistem tenaga harus tetap mampu menahan berbagai macam gangguan. Untuk itu, sistem tenaga listrik harus didesain dan dioperasikan sedemikian hingga sistem mampu terus beroperasi secara kontinu tanpa kehilangan beban serta tidak mengakibatkan pemadaman yang tidak terkontrol, meluas dan bertingkat apabila teriadi gangguan yang berat.

Akibat terjadinya gangguan maka keadaan sistem tenaga listrik akan berubah, dari keadaan yang lama ke keadaan yang baru periode singkat diantara keadaan yang lama dan keadaan yang baru disebut periode peralihan atau transien.

Selain tersedianya pembangkitan yang cukup, hal lain yang juga harus ditentukan adalah apakah kondisi transien jika terjadi gangguan akan mengganggu operasi normal sistem atau tidak 


\section{METODE PENELITIHAN}

\section{A. Metode}

Penelitian ini dilakukan selama kurang lebih7 bulan, yang dimulai pada bulan April 2018. Untuk pengambilan data penelitian dilakukan di PT. PLN (Persero) UPB Sulselrabar Makassar yang dimulai pada bulan Mei 2018.

Teknik analisis yang digunakan dalam penelitian ini adalah menggunakan metode kuantitatif dengan langkah langkah sebagai berikut :

1. Menghitung aliran daya menggunakan metode Newton Raphson sehingga diperoleh data tegangan dan sudut.

2. Hasil aliran daya tersebut menjadi data awal dalam menganalisis kestabilan transien

Dalam menyelesaikan analisis kestabilan transien pada sistem tenaga listrik Sulselrabar ini digunakan Matlab versi 2011 untuk memudahkan perhitungan.

Adapun langkah-langkah yang digunakan sebaga beikut :

1. Mempersiapkan data sistem generator.

2. Untuk keperluan aliran beban, Semua data impedansi diubah kedalam admitansi pengganti.

3. Menghitung aliran daya menggunakan metode Newton Raphson.

4. Menghitung tegangan internal semua generator dari hasil aliran daya seperti tegangan dan sudut tegangan pada bus generator maupun slack bus digunakan perhitungan stabilitas transien, demikian halnya dengan daya baik pada beban maupun generator.

5. Menghitung matriks admitansi setiap jaringan.

6. Memilih lokasi gangguan yang terkena gangguan hubung singkat.

7. Mencetak grafik perbedaan sudut rotor untuk setiap waktu pemutusan kritis.

Analisis kestabialan transient dengan Matlab ini meliputi perhitungan aliran beban dan grafik perbedaan sudut rotor untuk setiap waktu pemutusan kritis pada saat terjadi gangguan hubung singkat pada saluran Tello Tello Lama dan Tello - Sungguminasa dekat pembangkit yang sedang beroperasi.

Adapun flowchart program yang digunakan seperti terlihat pada gambar 1 .

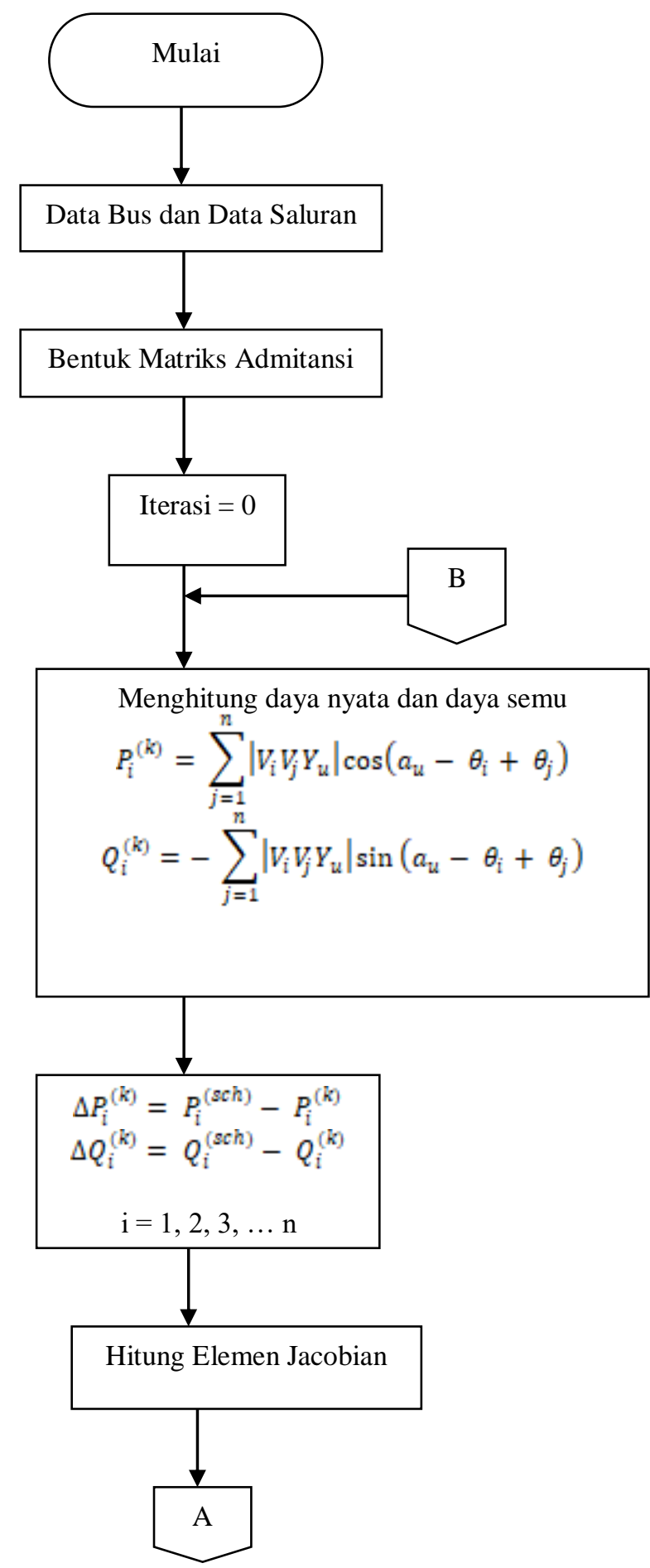

Gambar 1. Flow Chart Penelitian

\section{HASIL DAN PEMBAHASAN}

Dalam menyelesaikan analisis kestabilan transien pada sistem tenaga listrik Sulselrabar ini digunakan perangkat lunak Matlab 2011b untuk memudahkan perhitungan.

Penentuan sudut pemutusan kritis dan waktu pemutusan kritis dengan melihat hasil perhitungan software matlab komputasi. Adapun data dan kondisi kestabilan transien dianalisis pada suatu kondisi 
pembebanan tertentu, yakni pembebanan tanggal 1 Desember 2017.

Untuk analisis kestabilan transien sistem kelistrikan Sulselrabar diperlukan data bus, data saluran transmisi, data generator dan data pembebanan.

\section{A. Mencari Nilai Sudut Pemutusan Kritis}

Dalam mencari nilai sudut pemutusan kritis diperlukan data impedansi dan perhitungan dilakukan dengan menggunakan software matlab seperti yang diperlihatkan pada lampiran

Dari hasil komputasi matlab di peroleh nilai sudut dan tegangan dari tiap bus yang telah dilakukan perhitungan. Berikut tabel 1 hasil perhitungan aliran daya.

Table 1. Hasil Perhitangan Aliran Daya

\begin{tabular}{|c|c|c|c|c|c|c|}
\hline \multirow{2}{*}{$\begin{array}{l}\text { No } \\
\text { Bus }\end{array}$} & \multirow{2}{*}{$\begin{array}{l}\text { Teg } \\
\text { (p.u) }\end{array}$} & \multirow{2}{*}{$\begin{array}{c}\text { Sudut } \\
\text { (Derajat) }\end{array}$} & \multicolumn{2}{|c|}{ Beban } & \multicolumn{2}{|c|}{ Pembangkitan } \\
\hline & & & $\begin{array}{c}\mathbf{P} \\
(\mathbf{M W})\end{array}$ & $\begin{array}{c}\mathbf{Q} \\
\text { (MVAr) }\end{array}$ & $\begin{array}{c}\mathbf{P} \\
(\mathbf{M W})\end{array}$ & $\begin{array}{c}\mathbf{Q} \\
\text { (MVAr) }\end{array}$ \\
\hline 1 & 1.05 & 0 & 4 & 0.2 & 126,0 & $-4,0$ \\
\hline 2 & 1.0543 & 0.35781 & 7.5 & 2.7 & 0 & 0 \\
\hline 3 & 1.0545 & 0.41684 & 8.5 & 2.1 & 0 & 0 \\
\hline 4 & 1.0563 & 0.49741 & 12.7 & 4.4 & 0 & 0 \\
\hline 5 & 1.0559 & 0.46662 & 8.25 & 2.1 & 0 & 0 \\
\hline 6 & 1.0534 & 0.6336 & 23 & 0 & 40,0 & 12,2 \\
\hline 7 & 1.0514 & 0.20499 & 4.4 & 1.5 & 0 & 0 \\
\hline 8 & 1.0595 & 1.1560 & 12.2 & 5 & 0 & 0 \\
\hline 9 & 1.0616 & 1.7327 & 23 & 0 & 0 & 0 \\
\hline 10 & 1.0585 & 0.7585 & 21 & 8 & 26,0 & $-14,0$ \\
\hline 11 & 1.0517 & 0.48426 & 19.3 & -5 & 0 & 0 \\
\hline 12 & 1.0681 & 1.5318 & 38.6 & 11.6 & 0 & 0 \\
\hline 13 & 1.0533 & 0.38922 & 8.5 & -1.2 & 0 & 0 \\
\hline 14 & 1.0576 & 0.83943 & 32.6 & 6 & 0 & 0 \\
\hline 15 & 1.0561 & 065771 & 8 & 2.1 & 0 & 0 \\
\hline 16 & 1.0569 & 0.31696 & 14 & 10 & 0 & 0 \\
\hline 17 & 1.0521 & 0.20925 & 10.3 & 1.7 & 0 & 0 \\
\hline 18 & 1.0564 & 0.74656 & 25.6 & 5.7 & 0 & 0 \\
\hline 19 & 1.0536 & 0.43728 & 11.3 & 2.7 & 0 & 0 \\
\hline 20 & 1.0574 & 0.42911 & 5.3 & 3 & 0 & 0 \\
\hline 21 & 1.0588 & 0.54014 & 15.9 & 7.8 & 235.5 & -2.5 \\
\hline
\end{tabular}

Table 1. Hasil Perhitangan Aliran Daya (Lanjutan)

\begin{tabular}{|c|c|c|c|c|c|c|}
\hline \multirow{2}{*}{$\begin{array}{c}\text { No } \\
\text { Bus }\end{array}$} & $\begin{array}{c}\text { Teg } \\
\text { (p.u) }\end{array}$ & $\begin{array}{c}\text { Sudut } \\
\text { (Derajat) }\end{array}$ & $\begin{array}{c}\text { P } \\
\text { (MW) }\end{array}$ & $\begin{array}{c}\mathbf{Q} \\
\text { (MVAr) }\end{array}$ & $\begin{array}{c}\text { P } \\
\text { (MW) }\end{array}$ & $\begin{array}{c}\text { Q } \\
\text { (MVAr) }\end{array}$ \\
\hline 22 & 1.0855 & 0.15837 & 15 & 4.4 & 0 & 0 \\
\hline 23 & 1.0609 & 0.20195 & 8 & 6.9 & 0 & 0 \\
\hline 24 & 1.0553 & 0.60922 & 10 & 2.4 & 0 & 0 \\
\hline 25 & 1.0555 & 0.74794 & 7.2 & 0.9 & 0 & 0 \\
\hline 26 & 1.0557 & 0.37602 & 7.1 & 4.2 & 203.5 & 18.5 \\
\hline 27 & 1.0557 & 0.4423 & 8.5 & 2.2 & 0 & 0 \\
\hline 28 & 1.0542 & 0.39931 & 7.9 & 2.1 & 0 & 0 \\
\hline 29 & 1.0549 & 0.47406 & 5.8 & 1.4 & 0 & 0 \\
\hline 30 & 1.0533 & 0.39837 & 6.5 & 1.5 & 0 & 0 \\
\hline 31 & 1.0553 & 0.95691 & 17 & 1.9 & 0 & 0 \\
\hline 32 & 1.0502 & 0.053933 & 0 & 0 & 0 & 0 \\
\hline 33 & 1.0506 & 0.090364 & 2.1 & 0 & 0 & 0 \\
\hline 34 & 1.0582 & 0.81078 & 19 & 4.5 & 0 & 0 \\
\hline 35 & 1.0577 & 0.77063 & 32.8 & 0 & 0 & 0 \\
\hline 36 & 1.0511 & 0.10714 & 0 & 0 & 0 & 0 \\
\hline 37 & 1.0524 & 0.18567 & 5.8 & 1 & 0 & 0 \\
\hline 38 & 1.076 & 1.5489 & 45 & 11.4 & 0 & 0 \\
\hline
\end{tabular}

Gangguan transien yang disimulasikan adalah gangguan hubung singkat 3 fasa pada bus Tello $150 \mathrm{kV}$. Critical Clearing Time dapat ditentukan dengan melihat grafik sudut rotor. Semakin lama waktu gangguan terjadi maka grafik akan memperlihatkan respon sudut rotor yang akan semakin menuju ke kondisi tidak stabil. Komputasi kestabilan transien ini diperoleh dengan bantuan software Matlab. Adapun hasil dari komputasi dapat dilihat pada gambar 2.

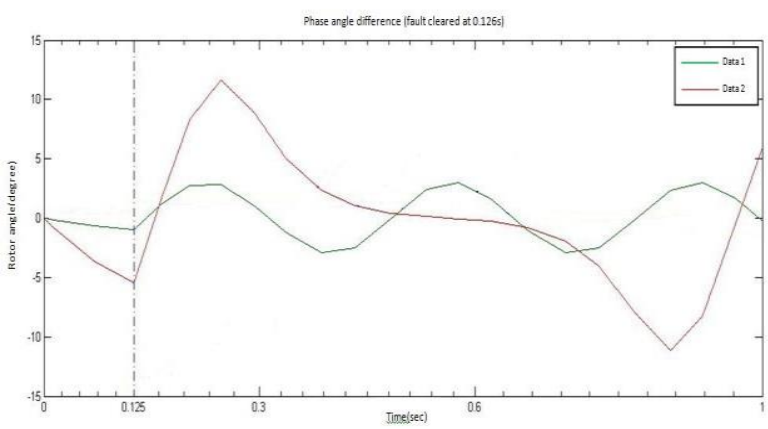

Gambar 2. Respon Sudut Rotor pada Saat Terjadi Gangguan pada Bus 11

(lama gangguan $=0.125$ detik), saluran $10-11$ 
Keterangan:

Data $1=$ Generator Bakaru

Data $2=$ Generator Suppa

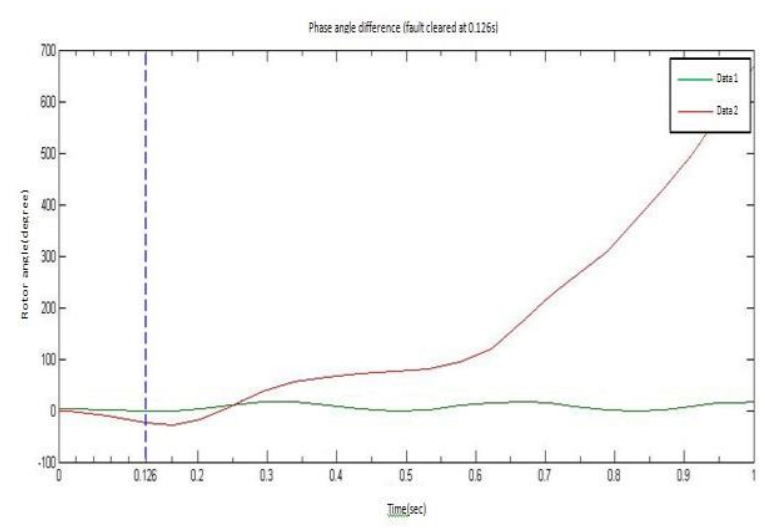

Gambar 3. Respon Sudut Rotor pada Saat Terjadi Gangguan pada Bus 13

(lama gangguan $=0.126$ detik), saluran $10-13$

Keterangan:

Data $1=$ Generator Bakaru

Data 2 = Generator Suppa

Untuk menganalisis kestabilan sistem dilihat perubahan beban sudut rotor generator pada slack bus (Bakaru). Waktu pemutusan kritis yang dipilih adalah waktu saat gangguan diputuskan tidak mempengaruhi kestabilan sistem atau tidak ada salah satu generator yang hilang kesinkronannya. Apabila ada perbedaan sudut rotor yang naik tidak terbatas pada salah satu generator, sistem tersebut dikatakan tidak stabil.

Grafik yang diperoleh dari hasil komputasi kestabilan transien sistem interkoneksi Sulselrabar dengan pemilihan waktu pemutusan kritis dapat dijelaskan sebagai berikut:

Gambar 2 adalah gangguan hubung singkat yang terjadi pada saluran Tello - Tello Lama selama 0.125 detik. Terlihat sudut rotor sudah hampir menuju ke kondisi tidak stabil (generator tidak sinkron lagi).

Pada gambar 3 adalah gangguan hubung singkat yang terjadi pada Tello - Sungguminasa selama 0.126 terlihat sudut rotor pada generator Suppa sudah hamir ke kondisi tidak stabil (generator tidak sinkron lagi).

Tabel 2. Letak Gangguan dan Hasil Analisis

\begin{tabular}{|c|c|c|c|}
\hline No & $\begin{array}{c}\text { Letak } \\
\text { Gangguan }\end{array}$ & Saluran Bus & $\begin{array}{c}\text { Waktu } \\
\text { Pemutusan } \\
\text { Kritis (detik) }\end{array}$ \\
\hline 1 & $\begin{array}{c}\text { Bus Tello } \\
150 \mathrm{kV}\end{array}$ & Tello - Tello Lama & 0.125 \\
\cline { 3 - 4 } & $\begin{array}{c}\text { Tello - } \\
\text { Sungguminasa }\end{array}$ & 0.126 \\
\hline
\end{tabular}

Dari tabel 2 dapat dilihat bahwa pada saat terjadi gangguan disekitar saluran bus Tello $150 \mathrm{kV}$, Generator Suppa yang mengalami respon tercepat terhadap gangguan.
Hal ini terjadi karena nilai tegangan dalam generator dan daya mekanik masukan dari pembangkit Suppa lebih kecil dibandingkan dari pembangkit Bakaru.

Pada tabel 2 terlihat bahwa, pada saat terjadi gangguan di bus Tello Lama di saluran Tello - Tello Lama, mengakibatkan generator di bus Suppa mengalami gangguan tercepat dimana waktu pemutusan yang diperoleh adalah 0.125 detik. Hal ini disebabkan oleh jarak gangguan dari pembangkit yang lebih dekat dari pusat pembangkit Suppa.

Perbedaan waktu pemutusan kritis yang diperoleh tersebut disebabkan karena pengaruh letak titik gangguan, dimana hasil analisis menunjukkan bahwa jika gangguan yang terjadi semakin dekat dengan pembangkit, maka waktu pemutusan kritis yang diperoleh semakin cepat.

\section{KESIMPULAN}

1. Hasil simulasi memperlihatkan bahwa kestabilan sudut rotor dipengaruhi oleh beberapa hal yaitu:

a. Lama waktu gangguan mempengaruhi sudut rotor di semua pembangkit. Semakin lama gangguan maka akan membuat sudut rotor menuju kekondisi tidak stabil.

b. Letak gangguan mempengaruhi kestabilan sudut rotor dari pembangkit. Semakin dekat gangguan terjadi, maka waktu pemutusan kritis yang diperoleh semakin cepat, sehingga kecenderungan sistem tidak stabil semakin besar.

2. Dari hasil studi didapatkan bahwa waktu pemutusan kritis tercepat diantara 2 kasus yaitu di saluran Tello Tello Lama dan Tello - Sungguminasa maka yang tercepat adalah saluran Tello - Tello Lama sebesar 0.125 detik.

\section{UCAPAN TERIMA KASIH}

Ucapan terima kasih yang sebesar-besarnya kepada:

1. Kementerian Riset, Teknologi, dan Pendidikan Tinggi Republik Indonesia (Ristekdikti), atas bantuan dana penelitian sehingga penelitian ini dapat terwujud.

2. PT. PLN Persero Wilayah Sulawesi Selatan, Barat, dan Tenggara, atas bantuannya memberikan data-data yang diperlukan untuk penelitian ini.

3. LP3M Unismuh Makassar, atas saran dan supportnya sehingga penulis dapat menyelesaikan penelitian ini dengan baik.

\section{REFERENSI}

[1] Aprilia, Vina and Heri Gusmedi, "Analisis gangguan tiga fasa pada saluran transmisi," Universitas Lampung, vol 7, No. 3, 2012.

[2] Arjana, Gede, Ontoseno P,. and Ardyono P, "Analisis stabilitas transient pada sistem tenaga listrik dengan mempertimbangkan beban non-linear," Institut Teknologi Sepuluh November, Vol 1, No. 1, 2012.

[3] Bijang, L and Nathaniel, "Analisis waktu pemutusan kritis suatu sistem kelistrikan," Politeknik Negeri Manado, vol 12, No. 2, 2012.

[4] Cekdin, Cekmas, "Sistem tenaga listrik," Yogyakarta, Andi Media, 2007. 
[5] Kumara, Danar Tri, Ontoseno P., and Ketut A., "Analisis stabilitas transien pada sistem transmisi sumatera utara $150 \mathrm{kV}-275 \mathrm{kV}$ dengan penambahan PLTA Batang Toru 4 x $125 \mathrm{MW}$," Institut Teknologi Sepuluh November, vol 5, No. 2, 2016.

[6] Pongtiku, James A., "Analisis stabilitas transien untuk menentukan waktu pemutusan kritis sistem PLTA Sawangan," UNSRAT, vol 5, No. 2, 2016.

[7] Rezky, Prima Prahasta and Onteseno Penangsang, "Studi analisa stabilitas transien Sistem Jawa, Madura dan Bali, Institut Teknologi Sepuluh November, vol 5, No. 2, 2006.

[8] S. Sudirman, "Analisis sistem tenaga," Erlangga, Bandung, 2010.

[9] Stevenson, Wiliam D., "Analisis sistem tenaga listrik," Erlangga, Jakarta, 1984.

[10] http://www.cds.caltech.edu/ murray/amwiki/index.php/FAQ:_What _is_steady_state_error\%3F. 